\title{
ESTRUTURA E EVOLUÇÃO DAS BACIAS MESOZÓICAS EMERSAS DA MARGEM CONTINENTAL BRASILEIRA*
}

\author{
HILDEBERTO A. OJEDA Y OJEDA**
}

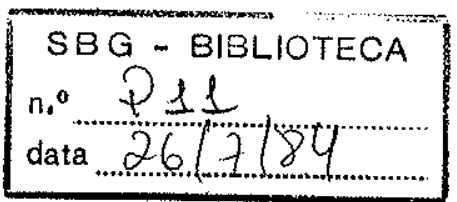

\begin{abstract}
The basic structural framework of the onshore Mesozoic Brazilian marginal basins is preferencially constituted by antithetic and synthetic tilted faulted blocks. Occasionally, less subsident blocks form intrabasinal highs, which some times are petroliferous. The complement of this framework is composed by shallow platforms, hinges and regional homoclines, as well as salt diapirs, shale incipient domes and growth faults with rollover.

The stratigraphic column of the basins is generally composed by a basal section of Paleozoic sediments, unconformably covered by Late Jurassic-Early Cretaceous continental deposits of the Dom João Stage. Conformably overlie Early Cretaceous (Rio da Serra to Jiquiá stages) fluvial-deltaiclacustrine sediments interbedded with syntectonic conglomerates. Unconformably overlie Early Cretaceous (Alagoas Stage) evaporitic or fluvial-lacustrine sequences. In the top of the column there are Albian-Tertiary marine-non marine sequences, which are composed by deltaic deposits, platform carbonates and slope carbonates, and clastics. Continental late Tertiary-Quaternary sediments as well as eruptive igneous rocks complete the stratigraphic section of the basins.

The geologic evolution of the focused basins reflects the events of the tectonic-sedimentary development of the Brazilian continental margin. Four principal phases were distinguished: intumescen$c e$, in the Late Jurassic-Early Cretaceous, with crustal uplift, development of peripheric basins and deposition of the Dom João Stage; rift, in the Early Cretaceous (Neocomian to Aptian), when rift valleys and antithetic and synthetic tilted fault blocks systems were formed, and the Rio da SerraJiquiá stages and a part of the Alagoas stage were deposited; transition, in the Early Cretaceous (Alagoas Age), when the first marine transgressions and deposition of evaporitic sequences occurred in some basins. In other basins, fluvial-deltaic-lacustrine sedimentation happened; and migration, in the Late Cretaceous (Albian)-Quaternary, when a generalized synthetic tilting and development of homoclinal structures (filled by and deposition of thick wedge of clastic-carbonatic-non marine and oceanic deposits) took place, and adiastrophic structures were formed.
\end{abstract}

INTRODUÇÃo O presente trabalho apresenta um resumo do arcabouço estrutural e da evolução tectono-sedimentar das bacias mesozóicas emersas da margem continental brasileira, adaptado ao modelo publicado recentemente por Ojeda (1982). Trata-se de um complemento a este trabalho, visando sua melhor compreensão por meio de maiores detalhes de geologia dessas bacias e de escala das ilustraçzes.

A maioria dessas bacias foi objeto de intensa atividade exploratória para petróleo, que permitiu uma definição bastante segura de seu arcabouço estrutural e interpretação de sua evolução geológica. A utilização de dados de métodos indiretos de prospecção (sísmica, gravimetria, magnetometria, eletrorresistividade etc.) e de investigaçăo direta, por meio de milhares de poços, oferece o necessário suporte a essas interpretaçóes e inferências.

O conceito básico, já estabelecido em trabalhos anteriores, é que a evolução do arcabouço estrutural das bacias marginais brasileiras, incluindo as bacias ora focalizadas, está intimamente relacionado com a evolução tectônica das placas Africana e Sulamericana. Mais especificamente, o arcabouço principal das bacias mesozóicas emersas formou-se diretamente associado à fase de fraturamento (tafrogênica) do continente Gondwana, no Eocretáceo (Ponte e Asmus, 1976).

As principais feiçðes estruturais diastróficas foram formadas por intenso falhamento normal e deposição concomitante de sedimentos flúvio-deltaico-lacustrinos (Ojeda, 1980).



Figura 1 - Bacias sedimentares brasileiras (Ojeda, 1981)

\footnotetext{
* Apresentado no Simpósio de Petróleo, promovido pela Petrobrás em 1981

** Petróleo Brasileiro S.A.-Petrobrás, Avenida Chile, 65, sala 1303, CEP 20000, Rio de Janeiro, RJ
} 


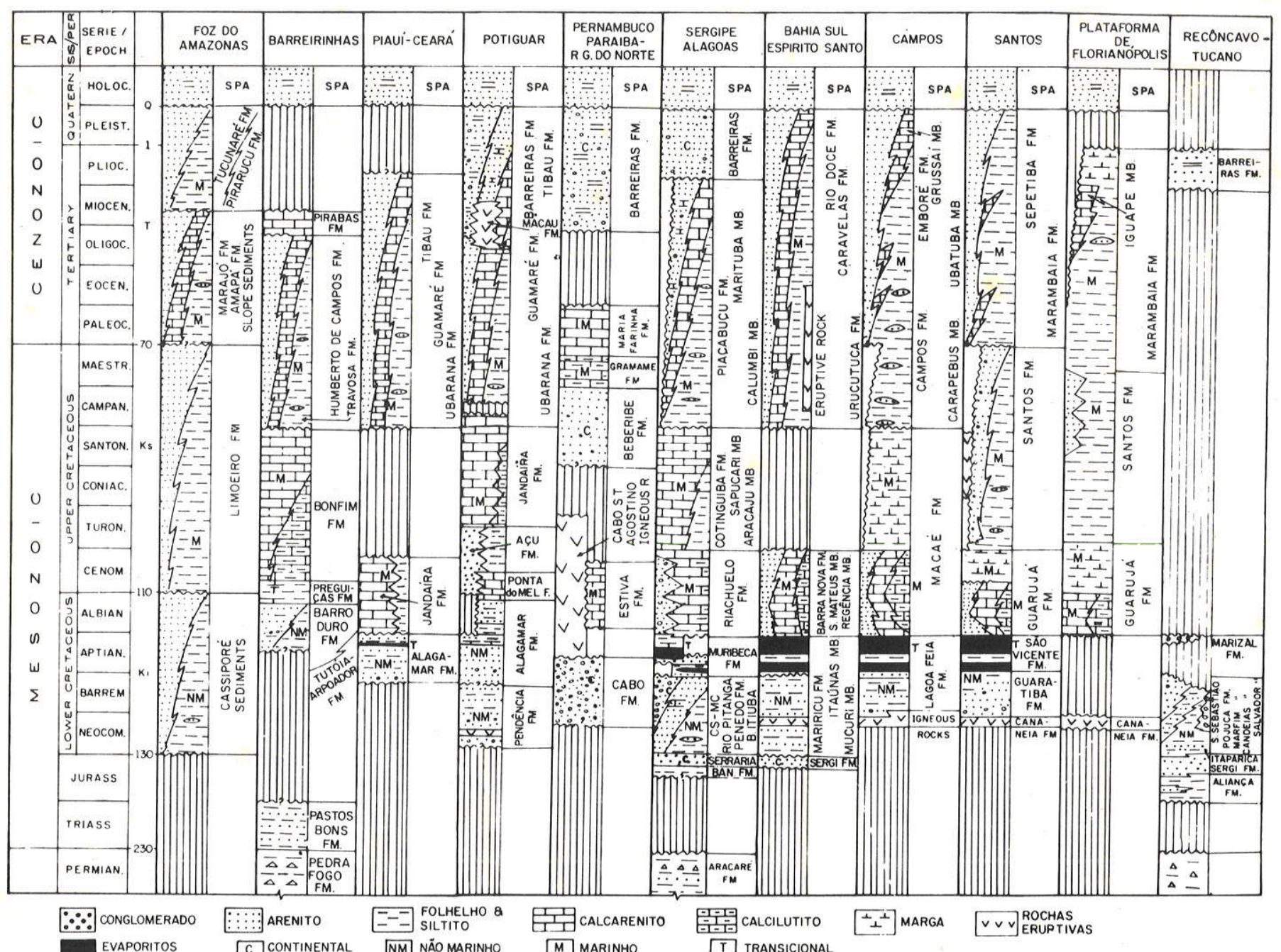

Figura 2 - Quadro cronoestratigráfico das bacias marginais brasileiras (Ojeda, 1981)

Nas fases tectônicas transicional e de migração divergente das placas, desenvolvidas entre o Neocretáceo e o Recente, o arcabouço estrutural básico das bacias emersas foi modificado pelo basculamento generalizado para norte ou leste, com desenvolvimento de charneiras-falhas e extensa estrutura homoclinal, sobre o qual se depositou espessa cunha de sedimentos clásticos e carbonáticos marinhos-não-marinhos.

A coluna estratigráfica das bacias está representada, basicamente, por sedimentos clásticos, carbonáticos e evaporíticos, que variam em idade entre o Paleozóico e o Quaternário. Rochas eruptivas, geralmente básicas, completam algumas seções (Fig. 2).

BACIA DE SÃo LUís Arcabouço estrutural A Bacia de São Luís é um extenso graben alongado noroeste-sudeste, situado entre as bacias de Bragança e Barreirinhas, na margem continental equatorial brasileira, ligado com a Bacia de Barreirinhas pelo Graben de Ilha Nova (Fig. 1).

A apresentação e a discussão do arcabouço estrutural serão feitas pelo mapa Bouguer, esboço tectônico generalizado, mapa estrutural ao nível da discordância pré-Formação Itapecuru e seção estrutural (Figs. 3 a 6).
MAPA BOUGUER Este mapa gravimétrico (Fig. 3) evidencia o alinhamento das bacias Bragança-São Luís-Barreirinhas orientado noroeste-sudeste e sugere possível ligação entre elas por meio de grabens estreitos e pouco profundos.

Um mínimo gravimétrico ( -100 miligals) coincide com a parte mais profunda do Graben pré-Cretáceo, que será focalizado depois.

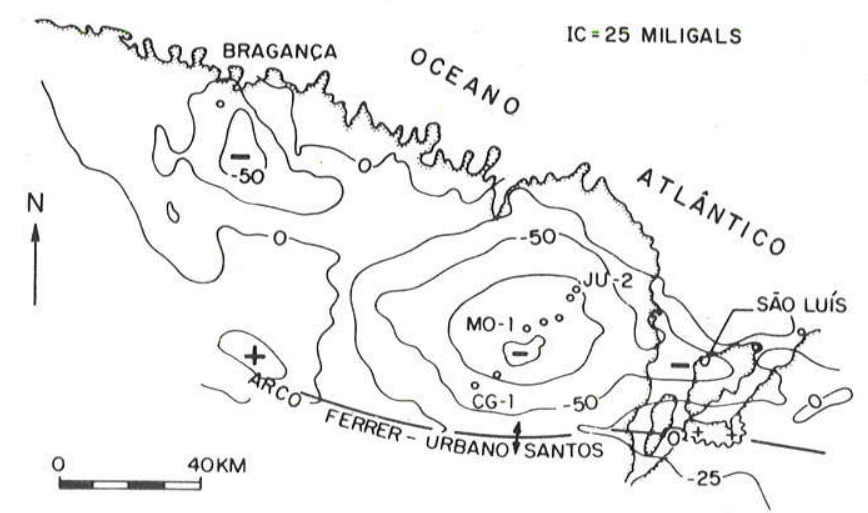

Figura 3 - Bacia de São Luís-Bragança: mapa Bouguer 


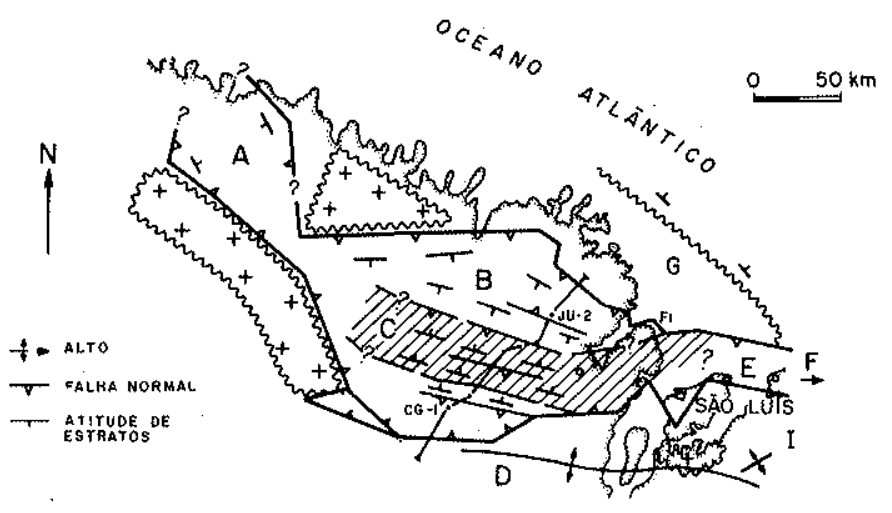

Figura 4 - Bacia de São Luis-Bragança. Arcabouço estrutural generalizado: $A-B a c i a$ de Bragança; $B-B a c i a$ de São Luis; C- Graben pré-Cretaceo; D-Arco Ferrer-Urbano Santos; $E$ - Graben de Ilha Nova; $F$ - Bacia de Barreirinhas; $G$ - Plataforma de llha de Santana; I - Alto de Bacaba (Ojeda, 1981)

\section{PRINCIPAIS FEIÇÕES ESTRUTURAIS O arcabouço} estrutural principal das bacias de São Luís e Bragança é formado pelas feiçðes Arco Ferrer-Urbano Santos e grabens de Ilha Nova, pré-Cretáceo e Cretáceo, as quais serão discutidas, resumidamente, em seguida (Fig. 5).

Arco Ferrer-Urbano Santos - Trata-se de uma expressiva feição, bem evidenciada por dados gravimétricos, sísmicos e subsuperfície, que separa a Bacia de São Luís da Bacia de Parnaíba. Estende-se para o sul, mergulhando suavemente, enquanto ao norte é interrompida abruptamente pela falha que limita, ao sul, a Bacia de São Luís (Fig. 5).

O flanco sul desta feição é recoberta por uma seção relativamente pouco espessa de sedimentos paleozóicos e cenozóicos enquanto, ao longo de seu eixo, só sedimentos cenozóicos de Formação Barreiras repousam de forma discordante sobre o Embasamento.

Graben de Ilha Nova - Esta estrutura falhada, alongada leste-oeste, constitui o prolongamento leste da Bacia de São Luís e faz sua ligação com a Bacia de Barreirinhas. É possível também que o Graben pré-Cretáceo se prolongue através desta feição.



Figura 5 - Bacia de São Luís. Seção geologica transversal $A-A^{\prime}$ : IT - Formação Itapecuru; PK - sedimentos pré-cretáceos; 1 - Arco Ferrer-Urbano Santos; 2 - graben pré-Cretaceo; 3 - Alto de Jerusalém; 4 - Plataforma de llha de Santana lOjeda, 1981)



Figura 6 - Bacia de São Luís. Mapa estrutural na discordância pré-Formaçao Itapecuru: $A$ - Graben pré-Cretáceo; $B$ - Graben de Ilha Nova; C - Plataforma de Ilha de Santana (Ojeda, 1981)

Graben Pré-Cretáceo - Esta é uma estrutura assimétrica, alongada oeste-leste, formada por falhas normais diretas e antitéticas (estas mais comuns na porção sul) com deslocamento às vezes superior a $1000 \mathrm{~m}$ (Fig. 5).

Este graben é preenchido por espessa sequiência de sedimentos clásticos finos, com intercalaçðes secundárias de arenitos finos a conglomeráticos. A idade desses sedimentos é incerta devido à ausência de fósseis-diagnósticos. Assim sendo, baseados apenas em sua posição e relaçðes estratigráficas e correlação litológica, esses sedimentos poderiam ser equivalentes às formações devonianas Longá e Pimenteiras da Bacia de Parnaíba ou, em última análise, à parte inferior da Formação Arpoador (Aptiana), da Bacia de Barreirinhas (Fig. 2).

MAPA ESTRUTURAL NA DISCORDÂNCIA PRE-FOR$M A C A \tilde{O} O$ ITAPECURU Neste mapa (Fig. 6), evidenciase claramente o Graben Cretácto, que, na realidade, representa a Bacia de São Luís propriamente dita. Trata-se de uma feição alongada noroeste-sudeste, limitada por falhas normais de grande deslocamento (às vezes superior a $1000 \mathrm{~m}$, especialmente na parte norte) (Fig. 5). Dentro do graben ocorrem horsts e grabens assimétricos menores, cujas falhas limitantes ocasionalmente "morrem" dentro da Formação Itapecuru.

Este Graben Cretáceo é preenchido por espessa seção (superior a $1000 \mathrm{~m}$ ) de sedimentos cretáceos flúvio-deltaico-lacustrinos, finos e grosseiros, da Formação Itapecuru.

Evoluçăo tectono-sedimentar $\mathrm{O}$ desenvolvimento do arcabouço estrutural principal da Bacia de São Luís foi controlado pelos eventos associados à fase de fraturamento do continente Gondwana, podendo ser sintetizado da seguinte maneira:

- Atividade tafrogênica no Paleozóico ou Eocretáceo (?) com formação do Graben pré-Cretáceo, o qual foi-concomitantemente (?) preenchido por sedimentos flúvio-deltaico-lacustrinos.

- Longo período erosivo, quanto foram removidas as fácies proximais da seqüêncịa pré-cretácea. 
- Tectonismo tafrogênico, com reativação de antigas falhas normais e desenvolvimento de novas falhas, formação do Graben Cretáceo e seu preenchimento concomitante por sedimentos flúvio-deltaico-lacustrinos da Formação Itapecuru. Ao findar essa fase, estavam também definidos o Arco Ferrer-Urbano Santos e a Plataforma de llha de Santana.

- Longa fase erosiva e subseqüente deposição da Formação Barreiras, terciária.

\section{BACIA DE BARREIRINHAS Arcabouço estrutu-} ral A Bacia de Barreirinhas é um extenso graben assimétrico, alongado oeste-leste, situado entre as bacias de São Luís e Piauí-Ceará (Fig. 1), na margem continental equatorial brasileira, ligado à Bacia de São Luís pelo Graben de Ilha Nova (Fig. 7).

$\mathrm{O}$ arcabouço estrutural básico foi formado na fase de fraturamento do Continente Gondwana, no Cretáceo, por meio de intenso falhamento normal e sedimentação concomitantes. Nessa ocasião, desenvolveram-se as mais importantes estruturas da bacia ou adjacências, tais como: o Arco FerrerUrbano Santos, as plataformas de Sobradinho e Ilha de Santana, o "Sinclinal" Menor e o Complexo Estrutural de Tutóia. Ainda nesta fase, foram desenvolvidas estruturas intrabacinais menores: diastróficas (horsts e grabens) e adiastróficas (diapiros de folhelho), que completam o arcabouço tectônico (Campos et al., 1974; Ojeda e Motta, 1976; Asmus e Ponte, 1976).

FEIÇÕES ESTRUTURAIS PRINCIPAIS O delineamento do arcabouço estrutural da bacia baseia-se, principalmente, no mapeamento sísmico de reflexão de vários horizontes feito por G. Jucá, em 1972 (Fig. 8). As feiçốs mapeadas mais significativas têm suficiente suporte de dados magnetométricos, gravimétricos, sísmicos de refração e de subsuperfície, podendo, portanto, ser consideradas representativas no embasamento cristalino.

Os principais elementos deformantes diastróficos são falhas normais diretas e antitéticas, que permitem definir plataformas rasas, blocos falhados escalonados, com e sem basculamento, e um eixo de inversão estrutural regional (Figs. 7 a 10). As principais feições estruturais podem ser assim focalizadas:

Arco Ferrer-Urbano Santos - Esta feição, já focalizada na Bacia de São Luís, estende-se paralelamente ao limite sul da Bacia de Barreirinhas, constituindo sua separaçăo com a Bacia de Parnaíba, paleozóica (Figs. 7 e 8).

Plataforma de Sobradinho - Esta estrutura constitui um degrau regional raso, mergulhando para o norte, localiza* do ao sul da Bacia de Barreirinhas, entre o Arco Ferrer-Urbano Santos e o "Sinclinal" Menor (Figs. 7 e 10). Seu limite norte é constituído pela Falha de Sobradinho, com rejeito superior a $1000 \mathrm{~m}$ (Figs. 8 e 9). Nesta feição regional, há estruturas menores, tais como: paleoaltos paleozóicos, altos cretáceos tardios, sub-bacias paleozóicas e pequenas estruturas dômicas tardias alinhadas paralelamente à Falha de Sobradinho (Figs. 7 e 8).

$O$ embasamento cristalino encontra-se relativamente raso, não mais que $1500 \mathrm{~m}$ no eixo das sub-bacias paleozóicas. Os estratos sobrejacentes incluem depósitos clásticos paleozóicos e- mesozóicos, com algumas soleiras de diabásio intercaladas (Fig. 2).

"Sinclinal" Menor - Esta é a feição regional mais significativa da Bacia de Barreirinhas, localizada entre a Plataforma de Sobradinho (ao sul) e o Complexo Estrutural de Tutóia (ao norte). Nas partes central e leste da bacia, esta feição, na realidade, é um graben assimétrico, mergulhan- do para o sul com seu alinhamento mais profundo correndo paralelamente ao plano das falhas de Sobradinho, Bar. reirinhas e Canoas (Figs. 7 e 9). Ao contrário, na porçăo oeste da bacia, trata-se de um extenso e complicado sinclinal, bastante afetado por falhamentos e estruturas transversais de natureza diastrófica e adiastrófica (alinhamentos diapíricos de folhelho).

As estruturas menores mais comuns e significativas são: 1. feiçð̃es dômicas alongadas, às vezes relacionadas com diapiros de folhelho e geralmente orientadas norte-sul; 2 . narizes estruturais ou pequenos rollovers associados a blocos baixos de falhas; e 3. pequenos blocos falhados, escalonados ou constituindo horsts e grabens, de preferência concentrados nas partes central e leste da bacia.

Complexo Estrutural de Tutóia - Esta é uma proeminente estrutura regional, ao norte do "Sinclinal" Menor, com a maior parte localizada na plataforma continental fronteiriça, com extensão de seu flanco para a bacia emersa (Figs. $7,9$ e 10$)$.

Trata-se de uma enorme estrutura positiva arqueada, localmente modificada por diapiros de folhelho, que constitui a culminação do graben assimétrico localizado em terra ("Sinclinal" Menor). Aparentemente, esta feição seria a extensão ocidental do Complexo Estrutural Atlântico, situado na parte distal das bacias de Piauí e Ceará, sob a plataforma continental atual (Miura e Barbosa, 1972; Ojeda e Motta, 1976), separado apenas por alinhamentos estruturais menores.

O núcleo do Complexo Estrutural de Tutóia é constituído por espessa seção de folhelhos da Formação Arpoador, seguramente superior a $3000 \mathrm{~m}$ (Fig. 2), com intercalação de seqủências turbidíticas.

Evoluçăo tectono-sedimentar $\mathrm{O}$ desenvolvimento do arcabouço estrutural-estratigráfico da Bacia de Barreirinhas foi basicamente controlado pelos eventos associados às fases de pré-fraturamento do Continente Gondwana e evolução das placas Sulamericana e Africana, entre o Eocretáceo e o Recente, podendo ser resumido da seguinte maneira:

- Sedimentação da sequêencia paleozóica em bacia rasa, intracratônica, platiforme (tipo I de Klemme, 1971).

- Acentuada atividade tectônica, com intenso falhamen. to e sedimentação concomitantes, no Eocretáceo, associado à fase de fraturamento do Continente Gondwana. Neste período, foram definidas algumas das principais feiçðes da



Figura 7 - Bacia de Barreirinhas. Arcabouço estrutural sintético: A - Complexo Estrutural de Tutoia; B - Plataforma de llha de Santana; C - Graben de Ilha Nova; D - "Sinclinal" Menor; $E$ - degrau de Sobradinho; $F$ - Alto de Bacaba (Ojeda, 1981) 


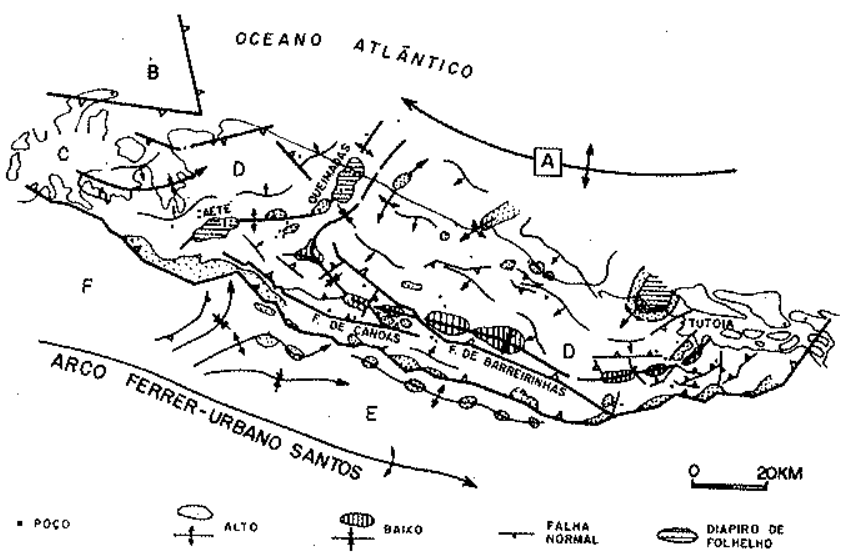

Figura 8-Bacia de Barreirinhas. Mapa estrutural sísmico de vários horizontes (Juca, 1972): A - Complexo Estrutural de Tutoia; $B$ - Plataforma de llha de Santana; $C$ - Graben de llha Nova; $D$ - "Sinclinal" Menor; $E$ - Plataforma de Sobradinho; $F-$ Alto de Bacaba (Ojeda, 198I)
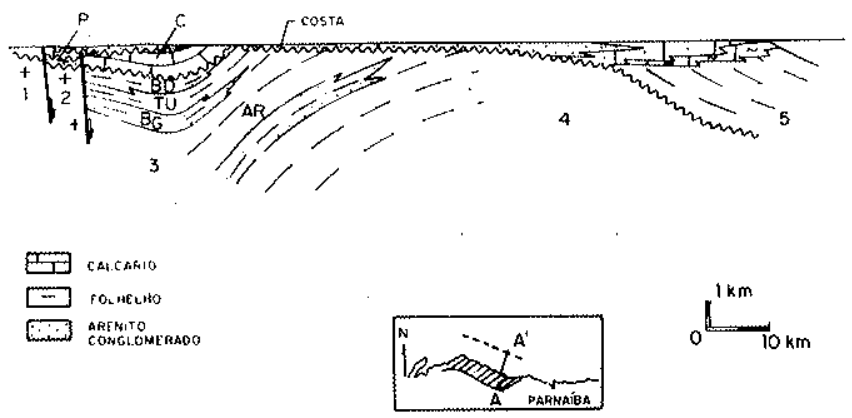

Figura 9-Bacia de Barreirinhas. Seção geologica transversal $A-A^{\prime}: 1$ - Arco Ferrer-Urbano Santos; 2 - Plataforma de Sobradinho; 3 - "Sinclinal" Menor; 4 - Complexo Estrutural de Tutoia; 5 - estrutural homoclinal; $C$ - Grupo Caju; BD - Formaçąo Barro Duro; TU - Formação Tutóia; BG - Formação Bom Gosto; $A R$ - Formaçao Arpoador; $P$ - seqüência paleozóica (Ojeda, 1981)
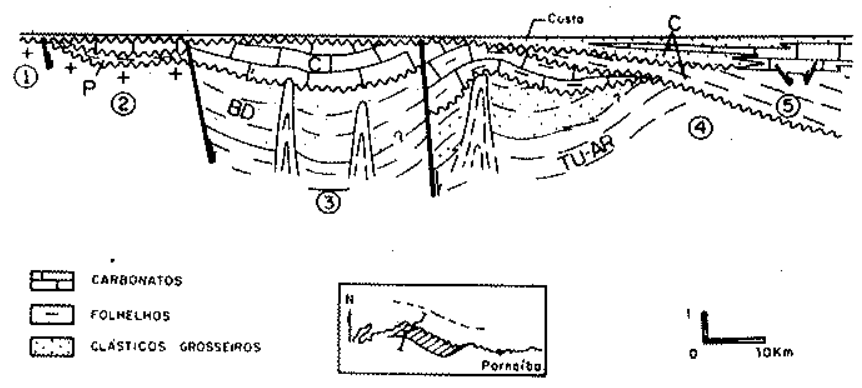

Figura 10 - Bacia de Barreirinhas. Seção geológica $B-B^{\prime}$ : $l$ - Arco Ferrer-Urbano Santos; 2 - Plataforma de Sobradinho; 3 - "Sinclinal" Menor; 4 - Complexo Estrutural de Tutóia; 5 - estrutura homoclinal; $C$ - Grupo Caju; $B D-$ Formaçao Barro Duro; TU - Formaçáo Tutoia; BG-Formação Bom Gosto; $A R$ - Formação Arpoador; $P$ - sequêencia paleozóica (Ojeda, 1981) bacia, tais como: falhas normais, horsts, grabens, plataformas e também intenso diapirismo de folhelho. Concomitantemente, depositaram mais de $6000 \mathrm{~m}$ de sedimentos clásticos flúvio-deltaico-lacustrinos do Grupo Canárias (Fig. 2).

- Erosão e subsequiente transgressão marinha, com deposição de espessa seqüência carbonática de plataforma e talude das formações Preguiças e Bonfim, no Neocretáceo. Nesse período, o sistema tafrogênico da fase anterior foi reativado, com desenvolvimento de falhas normais com rejeitos superiores a $2000 \mathrm{~m}$, manutenção de grabens assimétricos e sedimentação carbonática concomitante, ao longo das calhas controladas por esta tectônica sindeposicional (observar Fig. 10). O Complexo Estrutural de Tutóia alcançou seu máximo desenvolvimento.

- Soergimento e erosão regionais.

- Transgressão marinha, no Neocretáceo, que cobriu toda a Bacia de Barreirinhas até o Terciário. Nessa ocasião, foram depositados os sedimentos clásticos e carbonáticos de plataforma, ainda controlados por calhas mais subsidentes e antigas estruturas tafrogênicas. Ao longo da área da atual costa, da plataforma e do talude continental atuais, desenvolveu-se extensa estrutura homoclinal (devida ao basculamento da bacia para o norte e a intensa erosão) sobre a qual se depositaram clásticos e carbonatos da Formação Humberto de Campos, como depósitos de leques deltaicos, plataforma e depósitos de talude da Formação Travoṣa (Fig. 2) (Brown Jr. et al., 1976; Ojeda, 1982).

- Levantamento, erosão e subseqüente deposição dos sedimentos neoterciários e quaternários na atual área emersa da bacia.

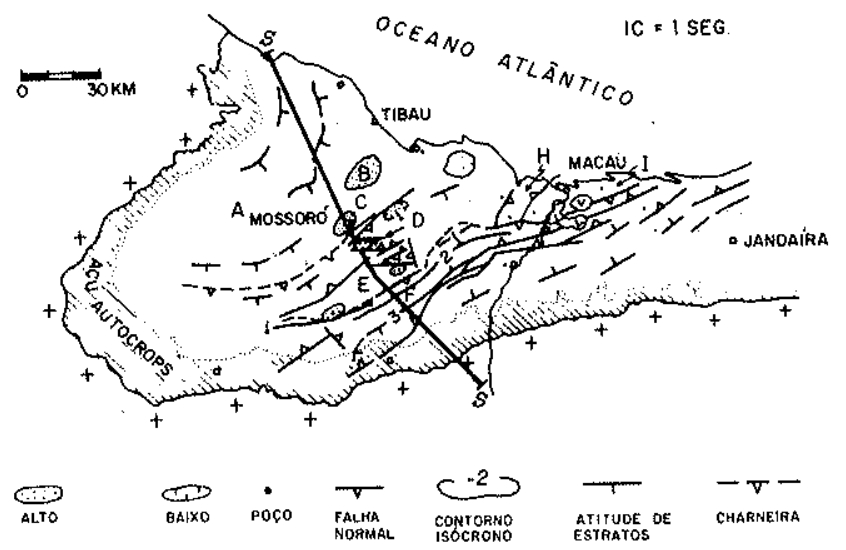

Figura 11 - Bacia Potiguar. Mapa estrutural sismico no topo do Embasamento: A - Plataforma de Baraúna; $B$ - Alto da Fazenda Belem; $C$ - Alto de Mossoró; $D$ - Graben de Apodi; $E-A l$ to de Quixaba; $F$ - Graben de Umbuzeiro; $G$ - Plataforma de Jandaifra; H - Graben de Pendência; I-Alto de Macau (Baccar, 1981; Ojeda e Santos, 1982)



Figura 12 - Bacia Potiguar. Seção geologica transversal $A-A^{\prime}$ : l - Plataforma de Baraúna; 2 - Alto de Mossoro; 3 - Graben de Apodi; 4-Alto de Quixaba; 5-Graben de Umbuzeiro; $P$ - Formaçáo Pendência (Zanotto, 1981) 




Figura 13 - Bacia Potiguar. Mapa estrutural na discordáncia Pré-Formação Açu: A - Plataforma de Baraúna; $B$ - Baixo de Apodi; $C$ - Alto de Quixaba; $D$ - Baixo de Pendência; $E$ - Plataforma de Jandaira (Ojeda, 1981; Guazelli et al., 1981)

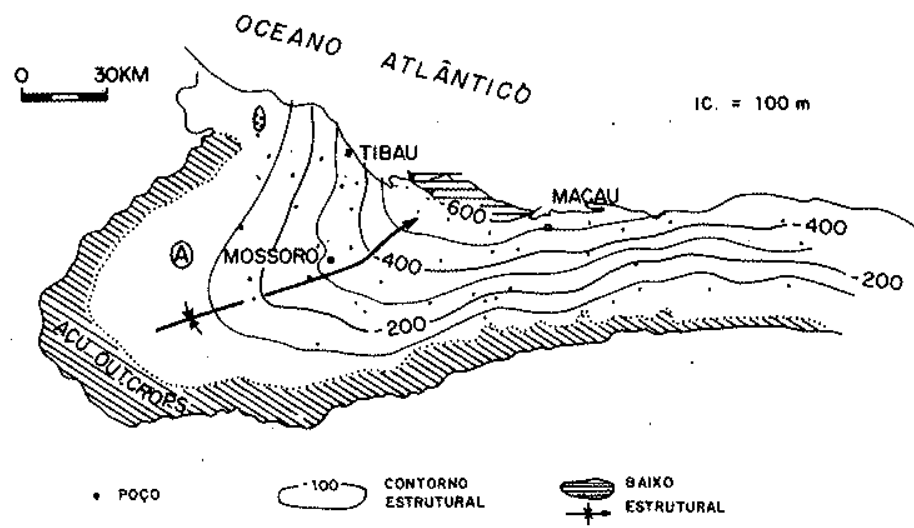

Figura 14 - Bacia Potiguar. Mapa estrutural na base da Formação Jandaira: A - Plataforma de Baraúna (Ojeda, 1981; Guazelli et al., 1981)

BACIA POTIGUAR Arcabouço estrutural A parte emersa da Bacia Potiguar é basicamente constituída por um sistema composto: plataforma-horsts-grabens, superimposto por extenso e amplo sinclinal, orientado sudoeste-nordeste, mergulhando para nordeste. Esta bacia situa-se entre o embasamento cristalino, adjacente à Bacia Piauí-Ceará, e o extremo norte da Bacia Pernambuco-Paraíba (Fig. 1).

$\mathrm{O}$ arcabouço estrutural mais antigo resultou dos eventos associados à fase de fraturamento do Continente Gondwana, no Eocretáceo. O mesmo desenvolveu-se por falhamentos normais diretos e antitéticos, especialmente intensos na parte central da bacia, com direção preferencial sudoeste-nordeste.

O preenchimento sedimentar é basicamente constituído por depósitos clásticos (flúvio-deltaico-lacustrinos) das formações Pendência e Açu, e depósitos carbonáticos (de plataforma e talude) da formação Jandaíra. Alguns derrames basálticos completam a estratigrafia da bacia. A idade atribuída a esses sedimentos varia entre o Eocretáceo e o Recente (Fig. 2) (Falkenhein et al., 1977).
PRINCIPAIS FEICOOEES ESTRUTURAIS DO EMBASA$M E N T O \quad O$ arcabouço estrutural da bacia é representado pelas feiçoes que afetam o embasamento cristalino, tais como: Plataforma de Baraúna e Jandaíra, grabens de Pendência e Apodi, e horst de Quixaba (Figs. 11 a 14) (Araújo et al., 1978).

Plataforma de Baraúna - Trata-se de uma ampla feição (aproximadamente $400 \mathrm{~km}^{2}$ ) localizada no noroeste da.bacia, com o embasamento relativamente raso, mergulhando suavemente para sudeste e nordeste (Figs. 11 e 12). Várias anomalias positivas foram esboçadas, algumas com pequenas acumulações de hidrocarbonetos em trapas estratigráficas ou combinadas, tais como Mossoró e Fazenda Belém.

A cobertura sedimentar é constituída por depósitos clásticos flúvio-deltaico-lacustrinos e carbonatos das for mações Açu e Jandaíra, respectivamente, que não ultrapassa os $1000 \mathrm{~m}$ de espessura (Fig. 12).

Meio grabens de Apodi e Pendência - Estas são as mais significativas estruturas assimétricas remanescentes que testemunham a atividade tafrogênica eocretácea da bacia, estando orientadas paralelamente sudoeste-nordeste, com pendor para nordeste. Essas estruturas apresentam preenchimento até de 1000 e $3000 \mathrm{~m}$ de sedimentos da Formação Pendência, respectivamente, encontrando-se recobertos, em discordância angular, por depósitos das formaçðes Açu e Jandaíra com espessuras inferiores a $1000 \mathrm{~m}$.

Horsts de Quixaba - Trata-se de uma feição assimétrica positiva, localizada entre os grabens de Apodi e Pendência, também orientada sudoeste-nordeste (Figs. 11 e 12). A cobertura sedimentar é constituída por sedimentos da Formação Açu, repousando discordantemente sobre o embasamento cristalino ou sobre delgado remanescente da Formação Pendência.

Plataforma de Jandaira - Esta estrutura é uma extensa feição rasa que ocupa grande parte da porção leste da bacia, mergulhando suavemente para noroeste. Encontra-se coberta por carbonatos da Formação Jandaíra, os quais não ultrapassam os $500 \mathrm{~m}$ de espessura.

ESTRUTURA NA DISCORDÂNCIA PRÉ $A C \zeta U$ A superfície da discordância pré-Açu é acentuadamente controlada pelo arcabouço tectônico da fase de fraturamento eocretácea subjacente. Consequientemente, as feições tafrogênicas, tais como as plataformas de Baraúna e Jandaíra, os grabens de Apodi e Pendência, e o horst de Quixaba, aparecem claramente refletidas no mapa estrutural deste horizonte (Fig. 13).

Clásticos da Formação Açu e carbonatos da Formação Jandaíra sobrejazem à discordância, alcançando espessuras entre 1250 e $1400 \mathrm{~m}$ na área superposta ao Graben de Pendência e à sua extensðo nordeste (Figs. 12 e 13).

ESTRUTURA NA BASE DA FORMAÇÃO JAN$D A f R A$ A estrutura regional neste nível estratigráfico é representada por um extenso e amplo sinclinal assimétrico, cujo eixo mergulha para nordeste (Fig. 14). As principais feiçðes tafrogênicas eocretáceas não são mais refletidas neste horizonte, estando mais ou menos delineadas as plataformas de Baraúna e Jandaíra.

A máxima cobertura sedimentar dos carbonatos da Formação Jandaíra chega a $650 \mathrm{~m}$ de espessura na parte centro. nordeste do sinclinal, na área costeira a oeste de Macau (Fig. 14). 
Evolução tectono-sedimentar A evolução do arcabouço estrutural estratigráfico da Bacia Potiguar (emersa) foi controlada pelos eventos associados ao desenvolvimento tectônico das placas Africana e Sulamericana, entre o Eocretáceo e o Recente, podendo ser assim resumida:

- A evolução tectônica iniciou-se com acentuada atividade tafrogênica e alguma atividade ígnea. Intenso falhamento normal direto e antitético deu lugár à formação dos grabens de Apodi e Pendência e ao horst de Quixaba. Concomitantemente, depositaram-se os sedimentos flúvio-deltaico-lacustrinos da Formação Pendência, no Eocretáceo, entre o Neocomiano e o Aptiano (Fig. 2). É provavel que durante o Aptiano tenha ocorrido a primeira incursão marinha, com deposição de evaporitos ao longo da parte mais profunda do Graben de Pendência, cujo registro, entretanto, ainda não foi atravessado por perfuraçōes.

- Levantamento e basculamento de blocos falhados, com erosão e remoção de grande parte dos sedimentos da Formação Pendência nas áreas mais elevadas.

- Depósitos dos clásticos flúvio-deltaicos da Formação Açu, em discordância angular com os estratos subjacentes da Formação Pendência albiano-cenomaniana.

- Basculamento da bacia para norte.

- Transgressão marinha (iniciada no Albiano-Cenomaniano) proveniente da atual plataforma continental, que recobriu gradativamente a bacia, alcançando suas partes mais elevadas no Turoniano-Santoniano. Depositaram-se, então, os carbonatos Jandaíra em contato gradacional com os clásticos subjacentes da Formaçăo Açu (Fig. 2).

- Soerguimento e erosão.

- Deposição dos sedimentos terciários Tibau e Barreirinhas como depósitos de leques deltaicos. O sistema deposicional complementar dessas unidades é constituído pelos sedimentos das formaçőes Guamaré e Ubarana. Nessa época, houve atividade ígnea efusiva representada pelos basaltos de Macau, intercalados com clásticos da Formação Barreiras (Fisher et al., 1975).

\section{BACIA DE SERGIPE-ALAGOAS Arcabouço estrutu-} ral A Bacia de Sergipe-Alagoas é basicamente um sistema de grabens assimétricos, orientados sudoeste-nordeste, recoberto por uma extensa estrutura homoclinal, mergulhando para sudeste (Fig. 1).

$\mathrm{O}$ arcabouço estrutural básico foi formado principalmente no Eocretáceo (Neocomiano-Barremiano), sendo controlado pelos eventos associados à fase de fraturamento do Continente Gondwana. Este arcabouço foi modificado entre o Aptiano e o Recente pelo basculamento e desenvolvimento da referida estrutura homoclinal, sobre a qual depositou espessa cunha de sedimentos marinhos-não-marinhos.

$\mathrm{Na}$ fase de fraturamento, o arcabouço estrutural principal (Eocretáceo) foi formado por intenso falhamento e sedimentaçăo concomitantes, com o consequiente desenvolvimento de dois sistemas de blocos falhados, assimétricos, escalonados e complementares, com basculamento sintético e antitético, com uma zona de inversão estrutural entre ambos (Ojeda, 1982).

O arcabouço estrutural da bacia será mostrado pelos mapas estruturais no embasamento cristalino, na base da Formação Muribeca e base do Membro Calumbi da Formação Piaçabuçu e seção geológica (Figs. 15 a 18).

ESTRUTURA DO EMBASAMENTO O mapa estrutural neste nível (Fig. 15) mostra o arcabouço principal da bacia, caracterizado por feiçðes tafrogênicas, tais como: plataformas, horsts, grabens e especialmente blocos falhados es- calonados, assimétricos, com basculamento sintético e antitético (Ojeda, 1982). As falhas limitantes são normais, diretas e antitéticas, com o bloco rebaixado para a bacia (sudeste), com rejeitos, em muitos casos superiores a $1000 \mathrm{~m}$ (Ojeda e Fujita, 1974).

As estruturas regionais de maior destaque são (Figs. $15 \mathrm{e}$ 16): Plataforma de Itaporanga, grabens assimétricos de Mosqueiro-Divina Pastora, Japaratuba, Piranhas, Ilha das Flores, Pontal de Coruripe, Maceió e Alagoas, altos de Sergipe, Palmeira Alta, São Miguel dos Campos e Paripueira, horsts de Penedo e Pacatuba, e o Domo de Igreja Nova.

ESTRUTURA NA BASE DA FORMAÇÃO MURIBE$C A \quad O$ mapa estrutural neste nível delineia as feiçðes da discordância pré-Muribeca (pré-aptiana), na Bacia de Sergipe, e da superfície de contato normal entre as formaçðes Ponta Verde e Muribeca, na Bacia de Alagoas (Figs. 2 e 17).

$\mathrm{Na}$ Bacia de Sergipe, a estrutura é fortemente controlada pelas principais feiçðes tafrogênicas sotopostas, já focalizadas. Muitas falhas foram reativadas e as seguintes feiçðes mais ou menos preservadas: Plataforma de Itaporanga, Alto de Sergipe, baixos de Japaratuba, Piranhas e Ilha das Flores, e horsts de Penedo, Japoatã (que constituíam o limite deposicional noroeste da Bacia Muribeca) e Pacatuba.

$\mathrm{Na}$ Bacia de Alagoas, o horizonte mapeado está incluído no sistema de blocos falhados com basculamento antitético pertencente ao periodo final da fase tafrogênica (no Aptiano). As feições principais, tais como os baixos de Maceió e Alagoas e o Alto de Paripueira, foram preservadas.

ESTRUTURA NA DISCORDÂNCIA PRÉ-CALUMBI O mapa estrutural deste nível estratigráfico (Fig. 18) representa um extenso homoclinal mergulhando para sul e sudeste, modificado por narizes anticlinais e sinclinais, os quais refletem antigas estruturas tafrogênicas pré-aptianas, tais como o Alto de Pacatuba e os baixos de Mosqueiro e Ilha das Flores (Ojeda e Fujita, 1974).

Sobre esta superfície homoclinal repousa espessa cunha de sedimentos clástico-carbonáticos, não-marinhos-marinhos da Formação Piaçabuçu, de idade campaniano-terciária (Fig. 2), com espessuras superiores a $1500 \mathrm{~m}$ nos baixos mais acentuados.

Evoluçăo tectono-sedimentar $\mathrm{O}$ desenvolvimento do arcabouço estrutural-estratigráfico da bacia foi controlado pelos eventos associados à evolução tectônica das placas Africana e Sulamericana, entre o Eocretáceo e o Recente, podendo ser assim resumido:

- Deposição de sedimentos paleozóicos em bacia intracratônica, platiforme (tipo I do Klemme, 1971).

- Levantamento e longo período erosivo.

- Deposição dos sedimentos do Grupo Brotas em bacia periférica adjacente à intumescência, no Neojurássico-Eocretáceo (Estrella, 1972).

- Grande atividade tafrogênica, no Eocretáceo (Neocomiano-Barremiano), com intenso falhamento e desenvolvimento de rift valleys adjacentes a um graben central (Ojeda, 1982), onde ocorreu a deposição concomitante de sedimentos flúvio-deltaico-lacustrinos do Subgrupo Coruripe e conglomerados sintectônicos da Formação Rio Pitanga (Fig. 2). Ao findar este período, estava definido o arcabouço estrutural principal da bacia.

- Levantamento e erosão na Bacia de Sergipe enquanto a Bacia de Alagoas continuava submetida à tafrogenia. Concomitantemente, dava-se a sedimentaçăo dos Evaporitos $\mathbf{P a -}$ ripueira, os quais constituem o registro da primeira incursăo marinha da bacia, no Eoaptiano (Schaller, 1969). 
- Extensa transgressão na Bacia de Sergipe, com deposição dos Evaporitos Ibura (com presença de sais radiativos), no Neoaptino, recobrindo a seção de conglomerados Carmópolis, criou condiçðes ideais para geração/trapeamento de hidrocarbonetos (Ojeda e Fujita, 1974; Szatmari et al., 1974).

- Basculamento da bacia para leste e sul, com desenvolvimento paulatino de extensa estrutura homoclinal.

- Deposição de espessa cunha de sedimentos não-marinhos-marinhos do Grupo Sergipe, no Albiano-Terciário, como depositos de leques deltaicos, de plataforma e talude, por meio de longos ciclos transgressivo-regressivos (Fisher $e t$ al., 1973).

- Levantamento e erosã̃o.

- Deposição dos sedimentos continentais, terciários, da Formação Barreiras e depósitos quaternários.

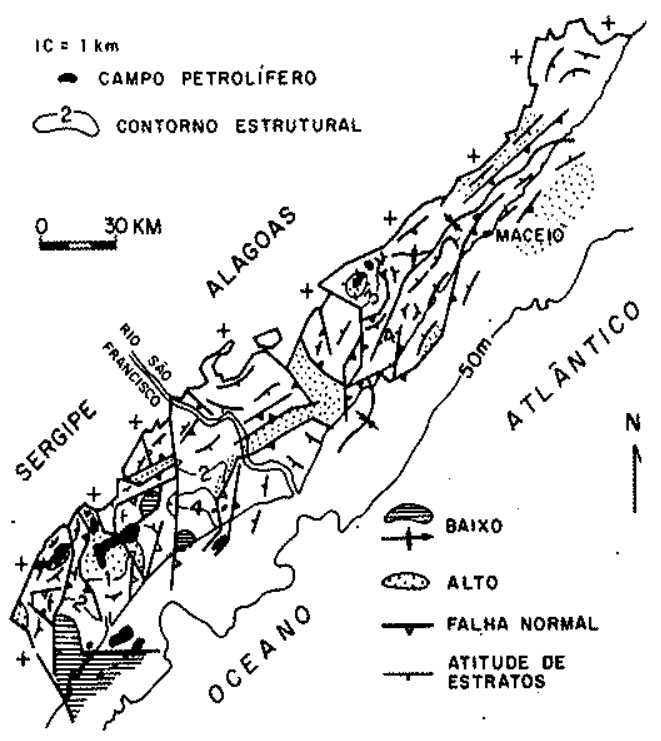

Figura 15 - Bacia de Sergipe Alagoas. Mapa estrutural do topo do embasamento (Ojeda e Fujita, 1974)
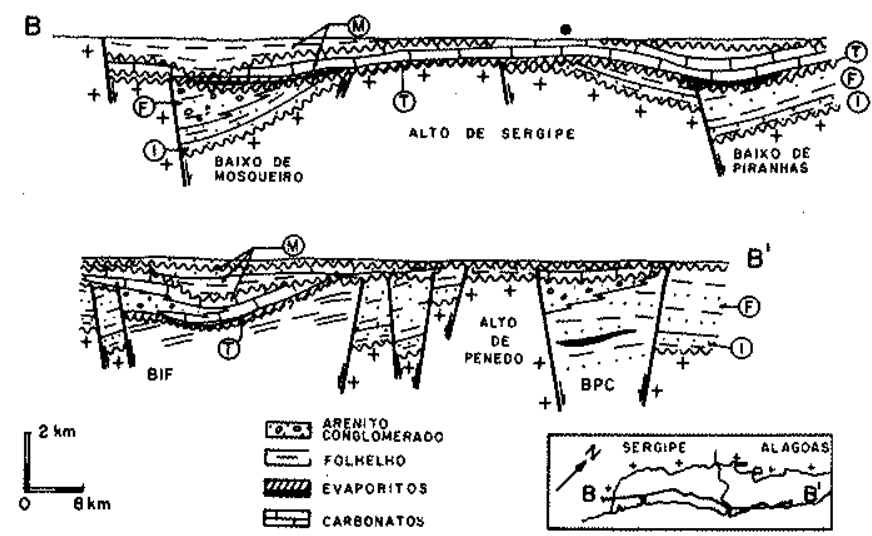

Figura 16 - Bacia Sergipe-Alagoas. Seçao estrutural B-B' (longitudinal): $M$ - fase de migraşao (oceânica: clástico-carbonática); $T$ - fase transicional (clástico-evaportica); $F$ - fase de fraturamento (clástica); I-fase de intumescimento (clástica); BPC Baixo Pontal de Coruripe; BIF - Baixo de llha das Flores (Ojeda e Fujita, 1974)

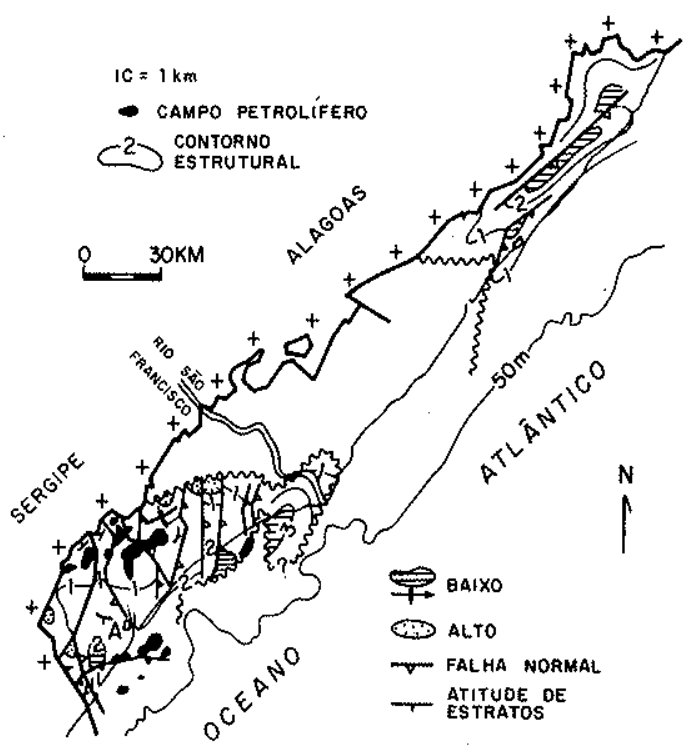

Figura 17 - Bacia de Sergipe-Alagoas. Mapa estrutural da base da Formação Muribeca: A - cidade de Aracaju (Ojeda e Fujita, 1974)

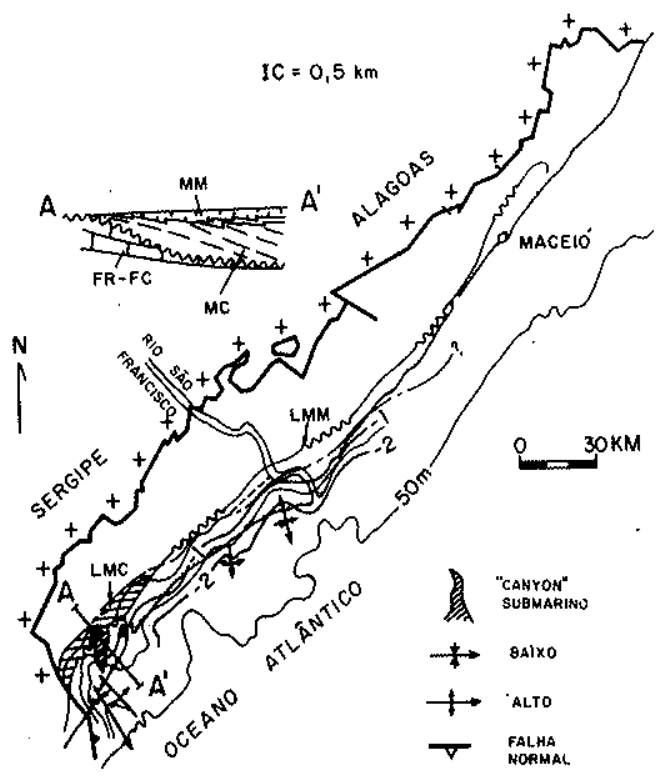

Figura 18-Bacia Sergipe-Alagoas. Mapa estrutural da discordancia Pré-Formaçáo Piaçabuçu: LMC - limite do Membro Calumbi; LMM - limite do Membro Marituba; FR - Formação Riachuelo; FC - Formaçao Cotinguiba; $M M$ - Membro Marituba; MC - Membro Calumbi (Ojeda e Fujita, 1974)

BACIA DO RECÓNCAVO-TUCANO Arcabouço es" trutural Trata-se de um graben assimétrico, alongado norte -sul, mergulhando para leste, que constitui uma ramificação tafrogênica do arcabouço estrutural da margem continental brasileira. Este arcabouço foi desenvolvido no Eocretáceo, como resultado dos eventos associados à fase de fraturamento do Continente Gondwana. Ao contrário das outras bacias focalizadas, os eventos das fases transicional $\mathrm{e}$ de migração praticament não se encontram refletidos nessa bacia. 
$O$ arcabouço estrutural assimétrico principal desenvolveu-se mediante intenso falhamento e sedimentação síncrona de espessa cunha de depósitos flúvio-deltaico-lacustrinos dos grupos Santo Amaro, Ilhas e Massacará (Figs. 20 a 23). A discussão e a apresentação do mesmo serão feitas por mapas estruturais, de isópacas e seções geológicas (Figs. 19 a 24).

FEICCOES REGIONAIS As feições estruturais regionais da Bacia do Recôncavo aparecem mais bem delineadas no mapa de isópacas do Andar Dom João (Fig. 19), como resultado da deposição do andar concomitantemente ao falhamento. Entre as feiçoes mais expressivas, incluem-se: os altos de Dom João, Mata-Catu, Cassarangongo, Patioba e Aporá, as plataformas Quiricó-Limoeiro e os baixos de Camaçari e Central. Deve-se ressaltar, ainda, que os altos de Dom João e Mata-Catu são importantes devido a seu alto conteúdo petrolífero, enquanto o Alto de Aporá é bastante significativo por secionar transversalmente a bacia e constituir a separação estrutural entre as bacias do Recôncavo e de Tucano.

ESTRUTURA DO EMBASAMENTO O arcabouço estrutural do Embasamento reflete-se no topo do Sergi (Figs. 21 e 22) e é mostrado nas seçðes geológicas (Figs. 20 e 23). As principais feições são formadas geralmente por falhas normais diretas, com bloco rebaixado para leste, constituindo um sistema de blocos falhados escalonados, com basculamento sintético para leste. Ocasionalmente, ocorrem falhas antitéticas, que dão lugar a altos intrabaciais, alguns altamente petrolíferos, como os de Dom João e Mata-Catu. Uma característica desses altos é a menor espessura de sedimentos em relação aos blocos adjacentes; o que demonstra seu desenvolvimento concomitante com a sedimentação (observar seçð̃es geológicas: Figs. 20 e 23).

A borda leste da Bacia Recôncavo-Tucano é formada por uma zona de falhas antitéticas, cujo rejeito total chega a $3000 \mathrm{~m}$. Nos blocos de falha rebaixados para oeste depositaram-se conglomerados sintectônicos de Formação Salvador, os quais se intercalam, para oeste, com sedimentos baciais profundos (folhelhos e turbiditos) da Formação Candeias e do Grupo Ilhas (Gama Jr., 1970).

ESTREUTURA NO GRUPO ILHAS O arcabouço estrutural nos estratos deste grupo pode ser representado pelo mapa ao nível do Marco 15 (Fig. 24), caracterizando-se basicamente por falhas normais diretas e algumas antitéticas. Um fato destacável é que muitas feiçðes diastróficas do Embasamento não se refletem no Grupo Ilhas, aparecendo, ao contrário, várias feiçőes adiastróficas. Assim sendo, as principais ocorrências tectônicas são: $a$ ) desaparecimento, sob o Marco 15, de falhas que afetam o Embasamento, 0 Grupo Brotas e a parte inferior do Grupo Santo Amaro; $b$ ) reativação, concomitante ou tardia à sedimentação do Grupo Ilhas, de algumas falhas do Embasamento; c) desenvolvimento de falhas de crescimento com rollover; e d) diapiros e intumescências de folhelho, ocasionalmente produtores de hidrocarbonetos.

As feiçðes regionais mais significativas delineadas no Marco 15 são: altos de Cassarangongo e Mata-Catu, Plata* forma Ouricó-Limoeiro e os baixos de Camaçari e Central.

Evoluçăo tectono-sedimentar $\mathrm{O}$ desenvolvimento de arcabouço estrutural principal da Bacia Recôncavo-Tucano foi controlado pelos eventos das fases de intumescência e fraturamento do Continente Gondwana durante o Neojurássico e o Eocretáceo. A evolução cronológica das ocorrências tectono-sedimentares pode ser assim resumida:
- Deposição da sequência paleozóica, em bacia platiforme (tipo I de Klemme, 1971; Asmus e Porto, 1972).

- Longo período erosivo, quando foi removida grande parte da seção paleozóica, ficando alguns remanescentes permianos representados pela Formação Santa Brígida.

- Desenvolvimento de bacias periféricas (tipo I de Klemme, 1971) onde se depositaram os sedimentos flúvio-lacustrinos não-marinhos do Grupo Brotas; no NeojurássicoEocretáceo (Estrella, 1972).

- Atividade tectônica tafrogênica, com intenso falhamento normal concomitante com a sedimentação e desenvolvimento dos sistemas de blocos falhados, com basculamento sintético e de alguns horsts intrabaciais. Nessas condiçбes,

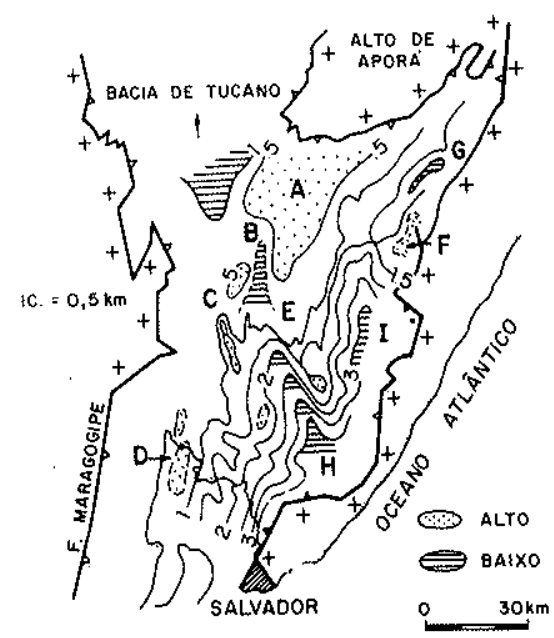

Figura 19 - Bacia do Recôncavo. Mapa de isópacas do Andar Rio da Serra (reflete estruturas regionais): $A$ - Plataforma Quirico-Lin moeiro; $B$ - Baixo de Alagoinhas; $C-$ Baixo de Cassarangongo; $D$ - Alto de Dom Joao; $E$ - Alto de Mata-Catu; $F$ - Alto de Patioba; $G$ - Baixo de Quiambina; $H-B a i x o$ de Camaçari; $I-$ Baixo Central (Dinter/Bahia)
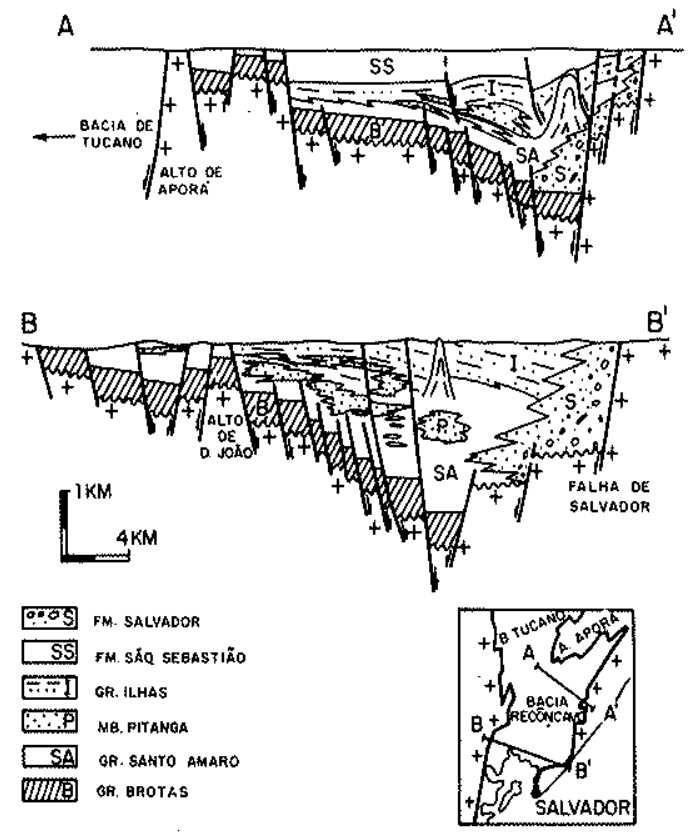

Figura 20 - Bacia do Recôncavo: seções geologicas transversais $A-A^{\prime}$ e $B-B^{\prime}$ (Dinter/Bahia) 




Figura 21 - Bacia do Recôncavo: mapa estrutural do topo da Formação Sergi (Dinter/Bahia)

depositou-se a espessa cunha de sedimentos clásticos flúviodeltaico-lacustrinos da Formação Santo Amaro e dos grupos Santo Amaro e Massacará (Ghignone e Andrade, 1970; Gama Jr., 1970).

- Desenvolvimento de falhas de crescimento com rollover, intumescências e diapiros de folhelhos, nas partes distais da bacia (flanco leste), concomitantemente com a sedimentação da Formação Santo Amaro e Grupo llhas.

- Intensa erosão e peneplanização.

- Deposição dos conglomerados Marizal como resultado de rejuvenescimento tectônico de áreas-fonte, no Aptiano (Idade Alagoas, local).

- Erosão e posterior deposição da Formação Barreiras, no Terciário, e sedimentos continentais no Quaternário.

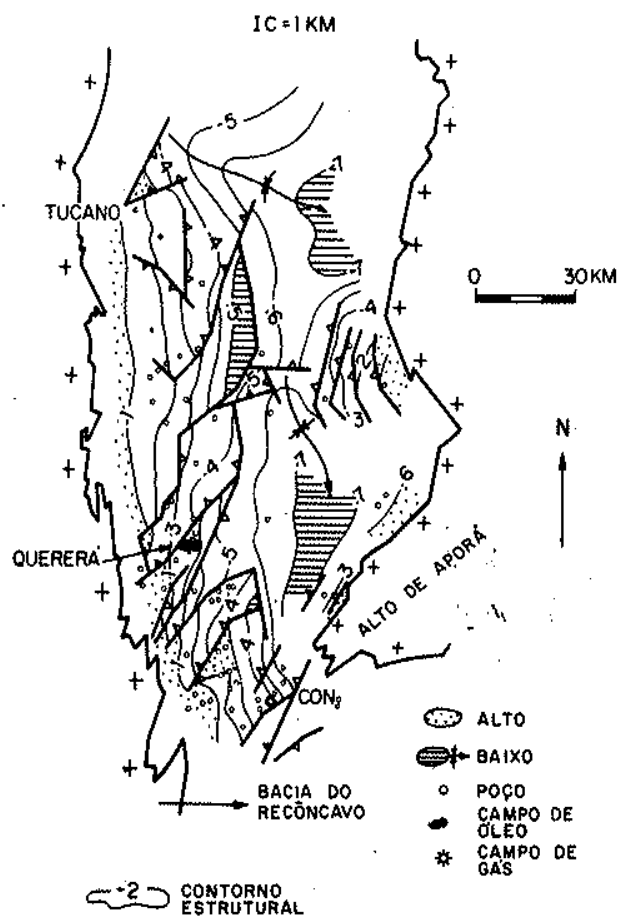

Figura 22 - Bacia de Tucano. Mapa estrutural doEmbasamento: CON - campo de gás de Conceicáo (Dinter/Bahia)


Figura 23 - Bacia de Tucano: seçóes estruturais transversais $C-C^{\prime}$ e $D-D^{\prime}$ (Dinter/Bahia)

BACIA DE ALMADA Arcabouço estrutural e estratigrafia Esta é uma pequena bacia emersa localizada ao sul da cidade de Salvador, constituindo a extensão sul do sistema estatigráfico-estrutural da Bacia do Recôncavo-Tucano.

O arcabouço estrutural principal foi desenvolvido no Eocretáceo, na fase de fraturamento do Continente Gondwana. As feiçð̌es representativas. são blocos limitados por falhas normais diretas e antitéticas, com direção preferencial noroeste-sudeste e nordeste-sudoeste (Figs. 25 e 26).



Figura 24-Bacia do Recóncavo: mapa estrutural do Marco 15 (Dinter/Bahia) 
A coluna estratigráfica da bacia é constituída por unidades eocretáceas, representadas por depósitos flúvio-deltaicolacustrinos dos grupos Brotas, Santo Amaro, Ilhas e Massacará. No topo da coluna ocorrem depósitos transicionais (proximais) da Formação Urucutuca (Fig. 24), de idade neocretácea-terciária, e delgada cobertura de sedimentos quaternários.

Evoluçåo tectono-sedimentar $\mathrm{O}$ desenvolvimento do arcabouço estrutural-estratigráfico da Bacia de Almada é similar ao da Bacia do Recôncavo-Tucano (ver "Evolução tectono-sedimentar" desta bacia).

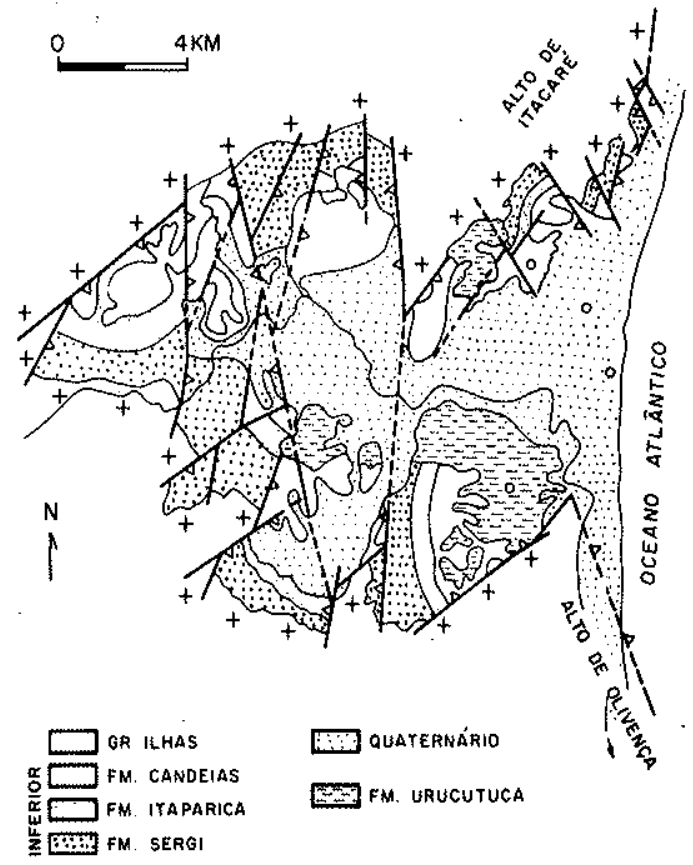

Figura 25 - Bacia de Almada: mapa geologico

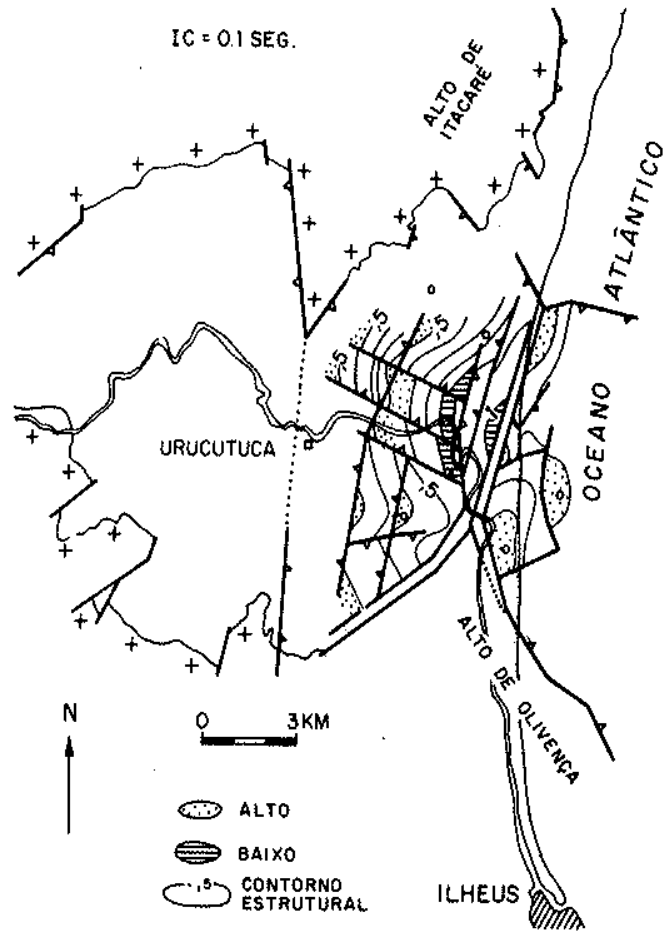

Figura 26 - Bacia de Almada: mapa estrutural do topo do Embasamento (Dinter/Bahia)
BACIA DE JEQUITINHONHA, MUCURI E ESPIRITO SANTO Arcabouço estrutural e estratigrafia Trata-se de bacias marginais, cuja parte emersa se localiza no sul do Estado da Bahia e Estado do Espírito Santo (Fig. 1). O desenvolvimento do arcabouço.estrutural, tal como nas outras bacias marginais brasileiras, está intimamente associado às fases de fraturamento do Continente Gondwana e migração divergente das placas Sulamericana e Africana.

$\mathrm{Na}$ fase tafrogênica, no Eocretáceo, o arcabouço principal foi formado por meio de horsts e grabens, com direção predominante norte-sul e basculamento preferencial para leste. $\mathrm{Na}$ fase de migração, este arcabouço foi completado mediante a definição de uma plataforma rasa, uma charneira e uma estrutura homoclinal crescentemente profunda (Dauzacker e Andrade, 1977).

A coluna estratigráfica da área emersa dessas bacias é constituída por sedimentos eocretáceos e quaternários, agrupados nas seguintes unidades: Formação Mariricu (depósitos flúvio-deltaico-lacustrinos do Membro Mucuri e evaporitos do Membro Itaúnas), Formação Barra Nova (depósitos de leques deltaicos do Membro São Mateus e carbonatos de plataforma do Membro Regência), Formação Urucutuca (depósitos de talude com turbiditos clásticos), Formação Caravelas (carbonatos de plataforma), Formação Rio Doce (depósitos de leques deltaicos), Formação Barreiras e sedimentos quaternários (Fig. 9). A coluna é completada por intercalação de rochas ígneas eruptivas (Ojeda, 1977) (Fig. 2).

A discussão do arcabouço estrutural será feita pelos mapas estruturais do embasamento e outros horizontes, e de seçðes geológicas (Figs. 27 a 29).

ESTRUTURA DO EMBASAMENTO Na Bacia do Espírito Santo, o arcabouço estrutural neste nível apresenta duas feiçôes claramente distintas: a bacia ou plataforma rasa e a bacia profunda. Ambas são separadas por uma linha de charneira, geralmente associada à falha, localmente com rejeito superior a $1000 \mathrm{~m}$ (Falha de Rio Doce-Fazenda Cedro) (Fig. 28).



Figura 27 - Bacia de Jequitinhonha: mapa estrutural sismico do topo do calcário da Formação Barra Nova (Dinter/Bahia) 


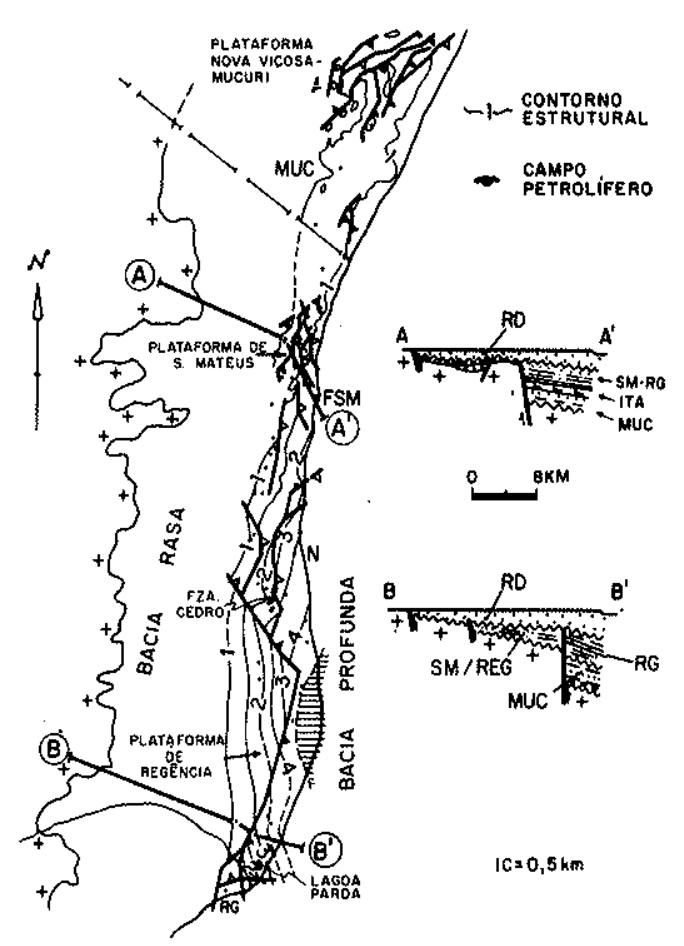

Figura 28 - Bacia de Mucuri-Espirito Santo. Mapa estrutural do topo do Embasamento: MUC - Mucuri; FSM - foz do Sao Mateus; $R G$ - Regência; RD - Formaçäo Rio Doce; SM-Membro São Mateus; IT - Membro Itaúnas; MUC - Membro Mucuri (Dinter/Macaé e Ojeda, 1981)

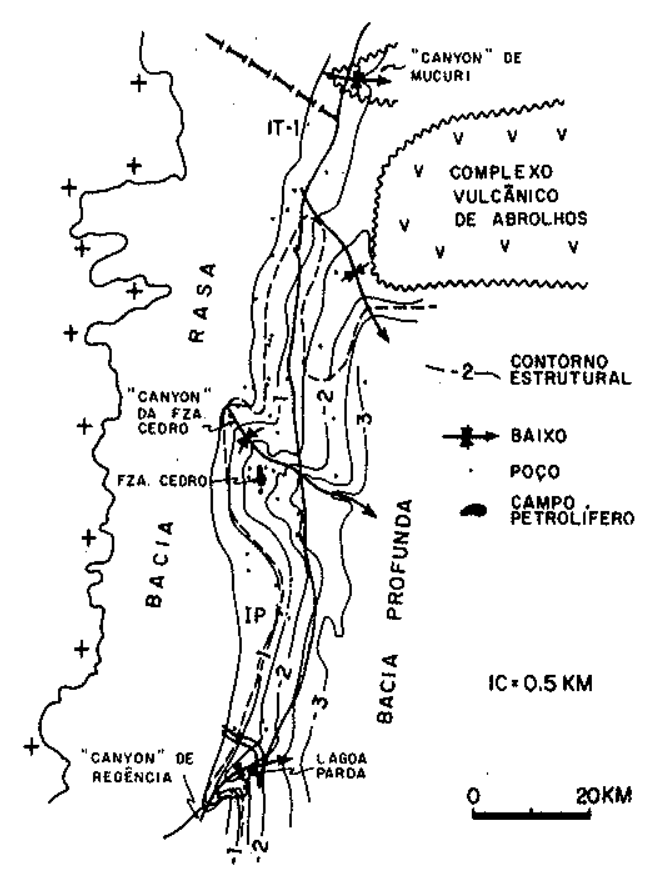

Figura 29 - Bacia de Mucuri-Esplrito Santo. Mapa estrutural na base do Grupo Espirito Santo: IP - Ipiranga; IT - Itaúnas (Din: ter/Macae e Ojeda, 1981)
Plataforma ou bacia rasa Esta feição ocupa a maior parte das bacias emersas de Mucuri e Espírito Santo. Nela inserem-se três plataformas menores: Nova Viçosa-Mucuri, São Mateus e Regência (Fig. 28). Essas feições encontram-se modificadas por horsts e grabens, de preferência orientadas norte-sul comumente basculadas para leste, sinteticamente (Ojeda, 1982). Pequenas estruturas dômicas desenvolvidas nos blocos falhados e testàdas por poços exploratórios acusaram resultados positivos, com a descoberta de campos de óleo de pequeno porte.

Bacia profunda Esta feição regional ocupa as porçðes central e sul da parte emersa da Bacia de Espírito Santo (Fig. 28). Está limitada a oeste pelas falhas-charneiras de Rio Doce e Fazenda Cedro e estende-se para leste sob a atual plataforma e talude continentais. A bacia profunda representa, na realidade, uma estrutura homoclinal basculada para leste, com pequenas anomalias de mergulho, preenchida por uma cunha sedimentar com espessura superior a $4000 \mathrm{~m}$, gradualmente crescente costa afora.

ESTRUTURA NOS CALCARIOS REGENCIA O arcabouço estrutural neste horizonte (Fig. 27) é representado principalmente por blocos falhados escalonados com basculamento sintético para leste e secundariamente por um nariz sinclinal com pendor para o sul.

ESTRUTURA NA BASE DO GRUPO ESPIRITO SANTO A estrutura regional refletida neste mapa (Fig. 29) é constituída por um extenso homoclinal mergulhando para leste, com profundidades que variam entre 1000 e $4500 \mathrm{~m}$ na área emersa da bacia. Localmente, esta feição é cortada por canyons submarinos pretéritos, tais como os de Mucuri, Fazenda Cedro e Regência. Cabe destacar, porém, que os dois últimos têm grande significado exploratório, já que condicionam, direta ou indiretamente, acumulações petrolíferas como as de Fazenda Cedro e Lagoa Parda.

Evolução tectono-sedimentar $\mathrm{O}$ arcabouço estrutural da bacia é basicamente o resultado do processo de fraturamento do Continente Gondwana, no Eocretáceo, sendo depois modificado pelos eventos tectônicos das fases transicionais e de migração das placas Sulamericana e Africana. Esta evolução geral da bacia pode ser resumida da seguinte maneira:

- Intumescimento da crosta continental com formação de hot spot e bacias periféricas (localizadas provavelmente fora da bacia de Espirito Santo) e erosão nas áreas mais soerguidas no Neojurássico-Eocretáceo.

- Fraturamento da crosta continental com formação de um provável graben central (au longo do bojo de intumescência) e um sistema de rift valleys adjacentes separados por um alto externo, orientados de preferência norte-sul durante o Eocretáceo (Ojeda, 1982). Deposição de sequiência flúvio-deltaico-lacustrina do Membro Mucuri da Formação Mariricu, concomitantemente às deformaçð̃es tafrogênicas.

- Erosão.

- Transgressão marinha e deposição dos Evaporitos Itaúnas, sob regime de quiescência tectônica, recobrindo uma superfície de erosão moldada em feiçðes tafrogênicas sotopostas.

- Ainda em condiçðes transgressivas, sedimentação do tract deposicional clástico-carbonático da Formação Barra Nova.

- Erosão. 
- Basculamento para leste, com definição da charneirafalha Rio Doce-Fazenda Cedro, plataforma rasa e estrutura homoclinal (bacia profunda).

- Deposição de espessa cunha de sedimentos neocretáceos-terciários das formaçð̃es Rio Doce, Caravelas e Urucutuca, como depósitos de leques deltaicos, plataforma e talude, respectivamente, sob regime de um megaciclo trans- gressivo-regressivo. Desenvolvimento dos paleocanyons submarinos de Mucuri, Fazenda Cedro e Regência (Ojeda et al. 1973; Ponte, 1973; Fisher et al., 1974; Ojeda, 1977; Ponte et al., 1978).

- Erosão.

- Deposição dos sedimentos continentais da Formação Barreiras.

\section{BIBLIOGRAFIA}

ARAÚJO, M.B., SOUZA, S.M. e GOMES, J.B. - 1978 - The Potiguar basin - General aspects and petroliferous prospects. Offshore Brazil 78: 02.5-02.11. Rio de Janeiro.

ASMUS, H.E. e PORTO, R. - 1972 - Classificaçảo das bacias sedimentares brasileiras segundo a tectônica de placas. Anais XXVI Congr. Bras. Geol., S.B.G., 2: 67-90, Belèm.

BACCAR, M. - 1981 - Mapa estrutural sismico no topo do embasamento - Bacia Potiguar. Depex, Petrobrás (inédito).

BROWN Jr., L.F., FUJITA, A.M. e TSUBONE, K. - 1976 - Depositional systems and petroleum potential in the Barreirinhas basin, northern Brazil. Rel. Int. Petrobrás/Dexpro/Divex, n? 5250. Rio de Janeiro.

CAMPOS, C.W.M., PONTE, F.C. e MIURA, K. - 1974 - Geology of the Brazilian continental margin. In: The geology of continental margins (C.A. Bark e C.L. Drake, eds.), pp. 447-461. Springer-Verlag, Nova York.

CARVALHO, K.W.B. - 1965 - Geologia da Bacia Sedimentar do Rio Almada. Bol, Téc. Petrobrás 8(1), Rio de Janeiro.

DAUZACKER, M.V. e ANDRADE, M.A. - 1977 - Bacias MucuriCumuruxariba: Prospectos exploratórios. Rel. Int. Petrobrás/ Dexpro/Divex, n. 4467, 19 p. Rio de Janeiro.

ESTRELLA, G.O. - 1972 - O estágio "rift" nas bacias marginais do lesie brasileiro. Anais XXVI Congr. Bras. Geol, S.B.G., 3: 29-34. Belém.

FALKENHEIN, F.U.H., ARAÜJO, M.B., SOUZA, S.M., GOMES, J.B. SOUZA, M.M. - 1977 - Relatório geológico, de progresso, da Bacia Potiguar. Rut. Ini..Petrobrás/Dexpro/Divex, n: 2785, 29 p. Rio de Janeiro.

FISHER, W.L., OJEDA, H.A.O. e GAMA Jr., E. - 1973 - Estratigrafia sismica e sistemas deposicionais da Formação Piaçabuçu. Anais XXVII Congr. Bras. Geol., S.B.G., 3: 123-134. Aracaju.

FISHER, W.L., MORALES, R.G., DELLA PIAZZA, H. e BROWN Jr., L.F. - 1974 - Sistemas deposicionais das bacias de Mucuri, Cumuruxatiba e Jequitinhonha. Anais XXVIII Congr. Bras. Geol., S.B.G., 1: 13-26. Porto Alegre.

FISHER, W.L., ESTRELLA, G.O. e GOMES, J.B. - 1975 - Sistema deposicional das formaçðes do Santoniano e Mioceno da Bacia Potiguar e suas relaçoes com exploração de óleo e gás. Rel. Int. Petrobrás/Dexpro/Divex, n: 4577, 45 p. Rio de Janeiro.

GAMA Jr., E. - 1970 - Modelo geológico das Bacias do Recóncavo e Tucano. Anais XXIV Congr. Bras. Geol, S. B.G., p. 191-200. Brasilia.

GHIGNONE, J.1. e ANDRADE, G. - $\$ 970-$ General geology and major oil fields of the Reconcavo basin. Publ. espec. da A.A.P.G. (Memoir 14), p. 337-358.

GUAZELLI, W. et al. - 1981 - Mapas estruturais na discordância Pré-Formaçao. Açu e na base da Formaçáo Jandaira. Petrobrás (inéditos).

JUCA, G. - 1972 - Mapa estrutural sismico de vários horizontes - Bacia de Barreirinhas. Petrobrás (inédito).
MIURA, K. e BARBOSA, J.C. - 1972 - Geologia da plataforma continental do Maranhào, Piaui, Ceará e Rio Grande do Norte. Anais $X X V I$ Congr. Bras. Geol., S.B.G., 2: 57-66. Belém.

OJEDA, H.A.O., FISHER, W.L. e GAMA Jr., E. - 1973 - Depositional systems of the Espirito Santo Group and Urucutuca Formation in the Espirito Santo basin: A preliminary report on genetic facies and petroleum potential. Rel. Int. Petrobrás/Dexpro/Divex, n? 4427, 20 p. Rio de Janeiro.

OJEDA, H.A.O. e FUJITA, A.M. - 1974 - Bacia de Sergipe/Alagoas. Geologia regional e perspectivas petroliferas. Anais XXVIII Congr. Bras. Geol., S.G.B., 1: 136-158. Porto Alegre.

OJEDA, H.A.O. e MOTTA, S. - 1976 - Bacias de Barreirinhas, Piaul e Ceará: Geologia regional e perspectivas petroliferas. Rel. Int. Petro* brás/Dexpro/Divex, no 5086. Rio de Janeiro.

OJEDA, H.A.O. - 1976-- Bacias Pernambuco-Paraiba-Rio Grande do Norte (Maragogi-Touros): Integraçăo geológica regional, perspectivas petroliferas e programa exploratório. Rel. Int, Petrobrás/Dexpro/ Divex, $n$ : 5240. Rio de Janeiro.

OJEDA, H.A.O. - 1977 - Bacia do Espírito Santo: Integração geológica regional (Rejatório de progresso). Rel. Int. Petrobrás/Dexpro/Divex, n: 5193. Rio de Janeiro.

OJEDA, H.A.O. - 1981 - Estrutura, estratigrafia e evoluçăo das bacias marginais brasileiras. Rev. Bras. Geoc. 11(4): 257.273.

OJEDA, H.A.O. e SANTOS, E.R. - 1982 - Bacia Potiguar (parte emersa): integraçào geológica regional de dados exploratórios. Rel. Int. Petrobrás/Depex/Sebat, n? 2186, 71 p. Rio de Janeiro.

PONTE, F.C. - 1973 - The Brazilian marginal basins: The ocean basins and margins, vol. 1 - The South Altantic. Plenum Press. Nova York, pp. 87-133.

PONTE, F.C. e ASMUS, H.E. - 1976 - The Brazilian marginal basin: current state of knowledge. Acad. bras. Cienc. 48 (Suplemento): 215-240. Sao Paulo, Brasil.

PONTE, F.C., DAUZACKER, M.V. e PORTO, R. - 1978 - Origem e acumulação de petróleo nas bacias sedimentares brasileiras. Congr. Bras. Petrol. 1: 121-147. Rio de Janeiro, Brasil.

SCHALLER, H. - 1969 - Revisão estratigráfica da Bacia de Sergipe/Alagoas. Bol. Téc. Petrobrás 12(1): 2I-86 Rio de Janeiro, Brasil.

SZATMARI, P., CARVAL.HO, R.S., SIMOES, I.A., TIBANA, P. e LEITE, D.C. - 1974 - Evaporitos de Sergipe: Geologia e geoquimica. Rel. Int. Petrobrás/Sen-BA/Sepes, Projeto Evaporitos, vol. 1, pp. 1-160.

ZANOTTO, D. - 1981 - Seçào geológica A-A' da Bacia Potiguar. Petrobrás (inédita).

MANUSCRITO

Recebido em 6 de janeiro de 1983 Revisăo aceita em 17 de agosto de 1983 